\title{
pro.posıções
}

http://dx.doi.org/10.1590/1980-6248-2017-0026

ARTIGOS

\section{Política de correção de fluxo escolar em Pernambuco: uma análise do programa Travessia ${ }^{12}$}

\section{School flow correction policy in Pernambuco: an analysis of the Travessia program}

\section{Política de flujo de corrección de la escuela en Pernambuco: un análisis de programa Travessia}

Edson Francisco de Andrade (i)

Silvana Galvão de Aguiar (ii)

(i) Universidade Federal de Pernambuco - UFPE, Recife, PE, Brasil. https://orcid.org/0000-00027577-898X, edsonfranciscodeandrade@gmail.com, edsonprofessor@uol.com.br.

(ii) Universidade Federal de Pernambuco - UFPE, Recife, PE, Brasil. https://orcid.org/0000-00023389-0383, silvana.galvao.mestre@gmail.com.

Resumo:
Analisamos no presente texto a percepção de alunos egressos do programa
Travessia acerca de possíveis repercussões qualitativas dessa política pública no
processo de enfrentamento da distorção idade/série escolar na rede de ensino de
Pernambuco. A análise dos dados permite-nos constatar que houve efetividade do
programa quanto ao processo de regularização do fluxo escolar, registrando-se
redução do índice de distorção idade/série escolar no ensino médio de $61 \%$ em
2007 para 36,4\% em 2013 . Por outro lado, com base no referencial de análise de
conteúdo, foi possível inferir dos dados coletados por meio da realização de
entrevistas semiestruturadas que há limitações no que se refere aos resultados
qualitativos, uma vez que os sujeitos da pesquisa reconhecem baixo impacto do
programa, no tocante a sequência dos estudos, a inserção no mundo do trabalho
formal e ao exercício de práticas cidadãs no contexto social em que os indivíduos
vivem.
Palavras-chave: política educacional, correção de fluxo escolar, programa
Travessia, fracasso escolar

1 Apoio: Conselho Nacional de Desenvolvimento Científico e Tecnológico (CNPq); Fundação de Amparo à Ciência e Tecnologia de Pernambuco (Facepe); Coordenação de Aperfeiçoamento de Pessoal de Nível Superior (Capes).

${ }^{2}$ Normalização, preparação e revisão textual: Mônica Silva (Tikinet) - revisao@tikinet.com.br. 


\begin{abstract}
:
We analyze, in the present text, the perception of students from the Travessia program about the possible qualitative repercussions of this public policy in the process of coping with the distortion of school age/grade in the teaching network of Pernambuco. The analysis of the data allows us to verify that the program was effective in the process of regulariaing the school flow, registering a reduction in the index of age/ school grade distortion in High School from 61\% in 2007 to 36.4\% in 2013. On the other hand, based on the ccontent analysis framework, it was possible to infer from the data collected through semi-structured interviews that have limitations in terms of qualitative results, since the subjects of the research recognize the low impact of the program, In terms of the sequence of studies, the insertion in the world of formal work and the practice of citizen practices in the social context in which individuals live.
\end{abstract}

Keywords: educational policy, school flow correction, Travessia program, school failure

\title{
Resumen:
}

Analizamos, en el presente texto, la percepción de alumnos egresados del programa Travessia sobre posibles efectos cualitativos de esta política pública en el proceso de afrontamiento de la distorsión edad/grado en el sistema escolar Pernambuco. El análisis de los datos nos permite ver que hubo efectividad del programa como el proceso de regularización de flujo de la escuela, registrando una reducción del indice de distorsión edad/grado en la escuela secundaria de un 61\% en 2007 a 36,4\% en 2013. Por otra parte, sobre la base de análisis de contenido de referencia, fue posible inferir a partir de los datos recogidos a través de entrevistas semiestructuradas que hay limitaciones en lo que respecta a los resultados cualitativos, ya que los sujetos reconocen programa de bajo impacto, con respecto a la secuencia de estudios, la inserción en el mundo del trabajo formal y el ejercicio de prácticas ciudadanas en el contexto social en el que viven los individuos.

Palabras clave: política educativa, corrección de caudal escuela, programa Travessia, el fracaso escolar

\section{Introdução}

No presente texto analisamos repercussões do programa Travessia, política educacional instituída no âmbito da rede pública de ensino de Pernambuco com a finalidade de reduzir a distorção idade/série escolar. Delimitamos o período de 2007 a 2013, que compreende os dois 


\section{pro.posıções}

http://dx.doi.org/10.1590/1980-6248-2017-0026

mandatos do governo Eduardo Campos, contexto histórico em que o programa foi instituído e desenvolvido ${ }^{3}$.

Pesquisas feitas em âmbito nacional, que tomaram direta ou indiretamente a implementação de políticas de correção do fluxo escolar como objeto de estudo (Cruz, 2007; Oliveira, 2002; Parente, 2002; Setúbal, 2000), chamam a atenção para o alto grau de incerteza quanto aos resultados esperados desse tipo de ação político-educacional, pois tem sido constatado que se trata de estratégia didático-pedagógica padronizada, portanto, que não leva em consideração a diversidade que constitui o contexto escolar a que se destina.

Com base em dados educacionais sobre o fluxo escolar no ensino médio em Pernambuco, foco da pesquisa que subsidiou este texto, o índice da distorção idade/série escolar nesta etapa de ensino era de $61 \%$ em 2007 , e foi reduzido para $36,4 \%$ em 2013 , conforme o Instituto Nacional de Estudos e Pesquisas Educacionais Anísio Teixeira (Inep, 2007, 2013). Fezse pertinente investigar, in loco, as percepções que as pessoas egressas do Travessia externam sobre esta política educacional, bem como os possíveis efeitos do programa em sua vida.

É sabido que o processo de melhoria da qualidade da educação pública no país deve contemplar ações que garantam o acesso e a permanência do aluno no sistema educacional, assumindo-se, como perspectiva, a superação do fracasso escolar - que tem sido revelado no baixo desempenho de aprendizagem, mas também nos altos índices de reprovação e evasão escolar e, por conseguinte, na descontinuidade de escolarização de parte significativa dos cidadãos.

Conceituar o fracasso escolar implica apreender múltiplos aspectos, tendo em vista as dimensões histórica, cognitiva, cultural, social e afetiva que integram a produção desse fenômeno. Cabe ressaltarmos que, inicialmente, o fracasso escolar foi apontado como problema psíquico, com a culpabilização das crianças e de seus pais. Em seguida, tem-se a concepção de problema técnico, com a culpabilização do professor. Aponta-se o fracasso escolar também como produção institucional, devido à lógica excludente da educação escolar. É pertinente reconhecermos que esse fenômeno é movido pela dimensão política intra e extraescolar: cultura escolar, cultura popular e relacõoes de poder (Angelucci, Kalmus, Paparelli, \& Patto, 2004).

\footnotetext{
${ }^{3}$ Os dois mandatos do governador Eduardo Henrique Accioly Campos correspondem ao período de $1^{\circ}$ de janeiro de 2007 a 4 de abril de 2014. Optamos por coletar dados correspondentes a anos letivos escolares completos. A pesquisa teve início em 2014, razão pela qual delimitamos o período de 2007 a 2013.
} 
O fato é que tem sido reconhecido como fracasso escolar o desajuste produzido em algum ponto do sistema educativo, envolvendo desde o desinteresse do próprio aluno aos problemas decorrentes do não cumprimento de incumbências institucionais por parte dos órgãos governamentais. Podemos considerar que esse fracasso se materializa quando o sistema educacional deixa de cumprir o previsto no artigo 22 da Lei de Diretrizes e Bases da Educação Nacional (LDB, no 9.394/1996), o qual estabelece que a educação básica tem por finalidades desenvolver o educando, assegurar-lhe a formação comum indispensável para o exercício da cidadania e fornecer-lhe meios para progredir no trabalho e em estudos posteriores.

Com efeito, o enfrentamento do fracasso escolar deve compreender ações que garantam a permanência e o desenvolvimento dos alunos nos processos didático-pedagógicos intraescolares, mas também deve envolver ações incumbidas de potencializar o desenvolvimento dos alunos no que concerne ao acesso e à progressão no mundo do trabalho e nos estudos subsequentes à educação básica.

Com base nesse entendimento, é pertinente problematizarmos a efetividade das políticas de caráter emergencial (a exemplo do programa em foco neste estudo), que, por buscarem resultados em curto prazo, acabam por vezes restringindo seus efeitos à correção da distorção idade/série escolar.

Considerando o que discutimos até aqui, apresentamos a questão central que nos orientou no desenvolvimento deste trabalho: o programa Travessia corrobora o processo de superação do fracasso escolar, na percep̧ão de seus alunos egressos?

Para compreender a que nos propomos, realizamos a pesquisa em duas etapas complementares. A primeira consistiu na coleta e análise de dados extraídos e compilados das sinopses estatísticas publicadas pelo Inep (2007-2013), a partir das quais mapeamos o curso histórico do fluxo escolar nos ensinos fundamental e médio, a fim de compreendermos a repercussão do programa Travessia na correção da distorção idade/série escolar no marco temporal da pesquisa. A segunda parte foi efetivada com entrevistas semiestruturadas ${ }^{4}$, envolvendo oito sujeitos, sendo quatro do sexo masculino e quatro do feminino. Foram

\footnotetext{
${ }^{4}$ Entende-se por entrevista semiestruturada "aquela que parte de certos questionamentos básicos, apoiados em teorias e hipóteses, que interessam a pesquisa, e que, em seguida, oferecem amplo campo de interrogativas, fruto de novas hipóteses que vão surgindo à medida que se recebem as respostas dos informantes. Dessa maneira, o informante, seguindo espontaneamente a linha do seu pensamento e de suas experiências dentro do foco principal colocado pelo investigador, começa a participar da elaboração do conteúdo da pesquisa” (Trivinõs, 1987, p. 146).
} 


\section{pro.posições}

http://dx.doi.org/10.1590/1980-6248-2017-0026

$e$-ISSN 1980-6248

incluídos no estudo os alunos egressos de escolas que cumpriram os seguintes critérios: (a) adotaram o programa Travessia no período delimitado no marco temporal da pesquisa; (b) apresentaram maior percentual de distorção idade/série no ano de início do programa; e (c) tiveram o maior índice de correção de fluxo escolar até o ano de 2013.

O trabalho analítico dos dados foi realizado por meio da análise de conteúdo. Tal perspectiva teve dois propósitos: compreender o dito e/ou registrado explicitamente na coleta de informações; e produzir inferências acerca de dados verbais ou simbólicos, isto é, efeitos da comunicação, das mensagens e também dos discursos captados pelo pesquisador. O exercício de produção de inferência é uma fase intermediária entre a descrição (enumeração das características do texto) e a interpretação (Bardin, 2007). No nosso estudo os participantes foram questionados sobre as percepções tanto de aspectos referentes à execução do programa Travessia, quanto de seus possíveis efeitos na vida desses sujeitos.

Justificamos a pertinência e relevância da difusão deste estudo por tematizar um fenômeno que vem recebendo atenção de pesquisadores da área educacional no país, mas que ainda não foi contemplado em estudo específico no contexto pernambucano. Por isso mesmo, acreditamos que os resultados aqui expostos podem subsidiar a defesa da melhoria da educação básica no Brasil, por meio da proposição de ações efetivas do poder público com vistas a superar o fracasso escolar, a partir da análise da experiência vivenciada no estado de Pernambuco.

\section{Correção de fluxo idade/série escolar: estratégias de ação do poder público}

Os programas com finalidade de corrigir a distorção idade/série escolar - destacandose, dentre outros, o programa Educar para Vencer, implantado nas séries finais do ensino fundamental no sistema municipal de educação de Salvador, Bahia (Cruz, 2007), e o programa Acelera Brasil, desenvolvido em redes municipais do país (Oliveira, 2002) - constituem um dos mecanismos adotados pelo poder público para justificar políticas de enfretamento do fracasso escolar. Este tem sido revelado tanto pelo atraso no percurso cronológico dos alunos em relação ao tempo desejável para a conclusão de cada etapa da trajetória escolar, quanto pelo baixo nível de aprendizagem, considerando o que se espera de construção de conhecimentos para cada série ou ciclo escolar. 


\section{pro.posıções}

http://dx.doi.org/10.1590/1980-6248-2017-0026

$e$-ISSN 1980-6248

Estima-se que mais de 3,8 milhões de crianças entre quatro e sete anos de idade e adolescentes estavam fora da escola no Brasil em 2010, segundo o Censo Demográfico do Instituto Brasileiro de Geografia e Estatística (IBGE, 2010). Outros 14,6 milhões de meninas e meninos entre 6 e 17 anos apresentavam atraso escolar, um dos principais fatores que ameaçam sua permanência na escola.

Tal constatação tem justificado a focalização de políticas de correção de fluxo escolar como passo prioritário para superar o fracasso nesse contexto. Dourado (2004), ao dissertar sobre esse tema, reconhece que um dos parâmetros para discutir a questão do fracasso escolar no Brasil é o conjunto de dados sobre o fluxo escolar, com índices de repetência, de evasão, de abandono e de distorção idade/série. Contudo, o autor acrescenta que a atenção às formas de acesso e permanência com sucesso escolar deve articular-se à discussão sobre "o papel social da educação e dimensões a serem asseguradas visando à garantia da qualidade social do processo formativo, bem como a articulação da escola a dinâmica social vigente no Brasil” (p. 12).

É importante salientar que a estratégia adotada pelas políticas públicas, com foco no enfrentamento da distorção idade/série escolar, tem sido baseada na redução do tempo de escolarização justamente para sujeitos sociais que foram excluídos do processo educacional em seu curso temporal desejável.

O modelo de programa de aceleração dos estudos que passou a subsidiar a elaboração de ações públicas em vários países, com propósito de viabilizar a correção de fluxo escolar, é o Accelerated Schools, proposto pela Universidade de Stanford, na Califórnia, Estados Unidos, que implementou a experiência com uma parcela de alunos que apresentavam históricos de multirrepetência e evasão escolar. O Brasil incorporou essa ideia desde 1992, trazida por Henry Levin, um dos fundadores desse programa ${ }^{5}$.

Essa lógica de ação do Estado, respaldada na experiência norte-americana de aceleração de estudos, foi amplamente difundida por meio de diversos programas e projetos nas unidades federativas do Brasil. Tomando por base o marco temporal da pesquisa que subsidiou este texto, observamos que houve significativa redução de taxas de distorção idade/série escolar no país, conforme podemos constatar nas Tabelas 1 e 2 :

\footnotetext{
${ }^{5}$ Para maiores informações sobre este tema, ver Levin e Soler (1992).
} 


\section{pro.posições}

Tabela 1 - Taxa de distorção idade/série, anos finais do ensino médio

\begin{tabular}{|l|c|c|c|}
\hline \multicolumn{1}{|c|}{ Região } & $\mathbf{2 0 0 7}$ & $\mathbf{2 0 1 1}$ & $\mathbf{2 0 1 3}$ \\
\hline Brasil & $42,5 \%$ & $32,8 \%$ & $29,5 \%$ \\
\hline Nordeste & $59,5 \%$ & $44 \%$ & $39,4 \%$ \\
\hline Sudeste & $31,1 \%$ & $24,9 \%$ & $21,6 \%$ \\
\hline Sul & $28,4 \%$ & $23,6 \%$ & $22,6 \%$ \\
\hline Centro-Oeste & $39,5 \%$ & $31,1 \%$ & $29 \%$ \\
\hline Norte & $60,5 \%$ & $48,3 \%$ & $45,2 \%$ \\
\hline Estado de Pernambuco & $61 \%$ & $44,3 \%$ & $36,4 \%$ \\
\hline Cidade do Recife & $59,8 \%$ & $41,8 \%$ & $34,2 \%$ \\
\hline
\end{tabular}

Fonte: Indicadores educacionais (Inep, 2007-2013)

Tabela 2 - Taxa de distorção idade/série, anos finais do ensino fundamental

\begin{tabular}{|l|c|c|c|}
\hline \multicolumn{1}{|c|}{ Região } & $\mathbf{2 0 0 7}$ & $\mathbf{2 0 1 1}$ & $\mathbf{2 0 1 3}$ \\
\hline Brasil & $31,6 \%$ & $22,9 \%$ & $27,5 \%$ \\
\hline Nordeste & $40,1 \%$ & $31,6 \%$ & $28,9 \%$ \\
\hline Sudeste & $17,4 \%$ & $15 \%$ & $14 \%$ \\
\hline Sul & $18,1 \%$ & $17,4 \%$ & $16,2 \%$ \\
\hline Centro-Oeste & $25,4 \%$ & $20,3 \%$ & $17,9 \%$ \\
\hline Norte & $49,9 \%$ & $34,2 \%$ & $31,3 \%$ \\
\hline Estado de Pernambuco & $38,6 \%$ & $28,5 \%$ & $25,8 \%$ \\
\hline Cidade do Recife & $35,2 \%$ & $23,5 \%$ & $21,5 \%$ \\
\hline
\end{tabular}

Fonte: Indicadores educacionais (Inep, 2007-2013)

Verificamos que a redução da taxa de distorção idade/série escolar no ensino fundamental no Brasil, no período de 2007 a 2013, foi de 4,1\%. Já em relação ao ensino médio, a redução foi de $13 \%$ nesse mesmo período. Notamos também que a região Norte registrava o maior índice de distorção do país no ano de 2007, seguida da região Nordeste. Ao mesmo tempo, observamos que em Pernambuco alcançou-se um percentual de 24,6\% de redução da distorção idade/série escolar no ensino médio, no período de 2007 a 2013.

Cabe ressaltarmos que a focalização da distorção idade/série escolar como problema solucionável por medidas de aceleração de estudos constitui uma afirmação equivocada de que o atraso na trajetória escolar é gerado pelos próprios indivíduos (Angelucci, Kalmus, Paparelli, \& Patto, 2004). Na realidade, o discurso que busca explicar a irregularidade do fluxo escolar como uma consequência natural da vulnerabilidade inerente às classes desprovidas socioeconomicamente omite outras dimensões importantes e geradoras desse fenômeno.

Para Arroyo (1997, p. 26), 


\section{pro.posıções}

http://dx.doi.org/10.1590/1980-6248-2017-0026

$e$-ISSN 1980-6248

... a ênfase dada nas últimas décadas ao fracasso escolar do aluno, faz com que se esqueça dessa dimensão político social e passa-se a buscar remédios na aceleração do aluno. ... O importante passa a ser a diminuição dos índices de fracasso e evasões, ainda que esse aluno nada aprenda, permanecendo mais uns meses nessa escola que pouco tem a dar, além da merenda escolar.

Com efeito, vale enfatizarmos outros fatores considerados como causas do fracasso escolar, a exemplo das condições socioeconômicas e das dimensões ideológica e institucional. Sobre essa matéria, podemos mencionar a manutenção de processos pedagógicos muitas vezes desvinculados das Diretrizes Curriculares Nacionais (2013), assim como a indiferença das práticas de gestão educacional aos anseios da comunidade escolar, além da perpetuação de precárias condições de infraestrutura oferecidas para aprendizagem nas escolas (Andrade, 2013).

Sobre as diversas dimensões da produção do fracasso escolar, Saviani (2003) acrescenta que a escola falha em seus objetivos por utilizar mecanismos pouco consistentes, sem avaliações e diagnósticos prévios, e ainda quando se distancia de sua função social: a transmissãoassimilação do saber sistematizado.

Apesar de a literatura da área reconhecer diversas dimensões que integram a discussão sobre fracasso escolar e perspectivas para superá-lo (Lugli \& Gualtieri, 2012), merece destaque o fato de que os programas e projetos desenvolvidos por municípios e estados, sob o discurso de enfretamento do fracasso escolar (por exemplo, Poronga, no Acre; Autonomia Carioca, no Rio de Janeiro; Floração, em Minas Gerais), na realidade têm sido executados, quase sempre, com o propósito estrito de corrigir o fluxo escolar . Desse modo, conferem destacável protagonismo a instâncias do terceiro setor, ou seja, institutos e fundações, organizações detentoras de tecnologias educacionais e de metodologias padronizadas (Granja, 2009), adotando nomenclaturas diferentes, como é o caso do programa Travessia, implantado em Pernambuco, conforme trataremos na seção a seguir.

\section{O programa Travessia}

O programa Travessia foi instituído como política pública em Pernambuco por meio da Instrução Normativa $n^{\circ}$ 07, de 15 de outubro de 2008, que “fixa diretrizes e orienta procedimentos para correção de fluxo escolar no Ensino Médio, no âmbito da Rede Pública Estadual de Ensino", implantado pelo governo Eduardo Campos em parceria com a Fundação 
Roberto Marinho (FRM) ${ }^{6}$. Cabe ressaltarmos que, em 2011, o programa estava presente em 179 dos 185 municípios do estado, com sua metodologia sendo utilizada em mais de 600 escolas da rede pública, totalizando 2,1 mil salas de aula.

Podemos considerar que, naquela conjuntura histórica e política em que o programa foi lançado no estado, havia manifesta intenção do governo estadual de reduzir custos com a máquina pública. Para tanto, recorreu-se ao discurso de que o Estado sozinho não mais comporta as demandas para corrigir o problema de fluxo escolar.

O artigo 11 da Instrução Normativa 07/2008 estabeleceu quatro módulos que estruturaram a organização pedagógica do programa Travessia, dispostos conforme os seguintes eixos temáticos: (a) o ser humano e sua expressão; (b) o ser humano interagindo com o espaço; (c) o ser humano em ação; e (d) o ser humano e a sua participação social. Para tanto, foi realizada uma rigorosa seleção de conteúdos e procedimentos didático-pedagógicos, tendo em vista o tempo cronológico exíguo pré-determinado para a conclusão do curso $^{7}$, em detrimento da composição curricular estabelecida para o ensino médio.

Para viabilizar sua grande promessa de reduzir o tempo do curso, o programa utiliza a já conhecida metodologia do Telecurso 2000, experiência que nasceu nos anos 1970, com o propósito de oferecer aulas pela televisão a milhares de brasileiros que precisavam concluir a escolaridade básica. A partir de 1995, por meio de uma parceria entre a Federação das Indústrias do Estado de São Paulo (Fiesp) e a FRM, advém o Novo Telecurso, incluindo novas disciplinas, mídias e novos livros com o objetivo de auxiliar os alunos a estudarem as disciplinas dos anos finais do ensino fundamental e do ensino médio.

Ao incorporar a metodologia de teleaulas já nessa etapa de execução do Novo Telecurso, o programa Travessia foi difundido com a promessa de privilegiar o estudo contextualizado, priorizando o desenvolvimento da oralidade, da escrita e da comunicação entre o grupo-classe, assim como o estímulo à criatividade do aluno. Para tanto, o próprio layout da sala de aula, organizada sempre em círculo, é anunciado como estratégia que proporciona a participação de

\footnotetext{
${ }^{6}$ A FRM foi criada em novembro de 1977 pelo jornalista Roberto Marinho e pertence ao Grupo Globo. Em 1980, a fundação colocou no ar pela Rede Globo o Telecurso $1^{\circ}$ e $2^{\circ}$ graus, que anos depois passou a se chamar Telecurso 2000, transmitindo conteúdos do ensino fundamental e médio através de programas de televisão e apostilas impressas.

7 A carga horária total do curso é de 1.600 horas letivas e contempla disciplinas das áreas do conhecimento: Linguagens, Códigos e suas Tecnologias, Ciências da Natureza, Matemática e suas Tecnologias e Ciências Humanas e suas Tecnologias (Instrução Normativa 07/2008).
} 


\section{pro.posições}

http://dx.doi.org/10.1590/1980-6248-2017-0026

$e$-ISSN 1980-6248

todos os alunos ao longo de todo o tempo pedagógico disponível. Após a exibição das teleaulas e a leitura de imagens, com o objetivo de estimular o conhecimento prévio dos alunos, a turma é dividida em quatro equipes com tarefas específicas: socialização, síntese, coordenação e avaliação. Os alunos fazem rodízio durante o curso, a fim de passarem por todas as equipes.

Os professores são responsáveis pela mediação pedagógica nas salas de aula, bem como pelos projetos didáticos complementares, com temáticas relacionadas, além de amostras culturais, aulas-passeio, entre outros. No entanto, não há envolvimento de professores, coordenadores e supervisores nos processos de planejamento e avaliação das ações pedagógicas, que ficam a cargo da FRM. Cada professor assume a responsabilidade por uma sala de aula do programa durante todo o curso. Já os supervisores são incumbidos de monitorar o programa, pois são eles que visitam regularmente as turmas, acompanhando e realizando as intervenções que julgarem necessárias (Secretaria de Educação do Estado, 2007).

Vale também ponderarmos que a proposição de classes aceleradas para os alunos do ensino médio, por parte da administração pública de Pernambuco, buscou responder a uma questão levantada pelo grupo político que assumira o governo naquela conjuntura histórica do estado: a necessidade urgente de enfrentar o quadro de elevada carência da mão de obra qualificada, para que Pernambuco pudesse levar adiante os seus projetos de desenvolvimento econômico.

Nas próximas seções analisaremos os depoimentos dos sujeitos da pesquisa, egressos do programa Travessia. Buscamos inferir os significados do programa à luz das percepções dos indivíduos, tanto em relação ao momento de execução dessa política educacional quanto à fase posterior, referente aos possíveis efeitos na vida dos alunos egressos.

\section{Expectativas projetadas sobre o programa Travessia}

Iniciamos a abordagem dos dados coletados no campo empírico da pesquisa com a análise das expectativas projetadas pelos alunos ao ingressarem no programa Travessia. Optamos por não revelar a identidade dos sujeitos envolvidos nessa pesquisa. Ao serem interrogados, no início das entrevistas, sobre qual sentimento traduziria sua expectativa ao ingressar no programa Travessia, cada sujeito mencionou um sentimento, a partir do qual foi possível atribuir os codinomes com que passamos a identificar os trechos dos depoimentos 


\section{pro.posições}

http://dx.doi.org/10.1590/1980-6248-2017-0026

\section{$e$-ISSN 1980-6248}

mencionados nesta seção do artigo. São eles: Realização; Superação; Confiança; Felicidade; Persistência; Esperança; Conquista; e Satisfação.

As expectativas de Realização ao entrar no programa eram que

o curso desse um incentivo a mais, que o programa estimulasse a turma em prosseguir, fazer uma faculdade e, assim, dar adiantamento aos estudos e não parar ali ... Naquela época eu pensava muita coisa: vou terminar meus estudos, fazer uma faculdade e agora vai dar tudo certo, vou poder transformar minha vida, sonhar com algo melhor para mim. Mas depois eu vi que o negócio era muito diferente. Aí pronto, fui botando os pés no chão, como diz a história, e tudo ficou inacabado, me senti sozinho, inclusive os sonhos. No momento das aulas, pensei: Acabou! ...

Esse depoimento de Realização é emblemático no conjunto das entrevistas concedidas pelos participantes, uma vez que evidencia estritamente o desejo de terminar o ensino médio como principal razão de ingresso no programa Travessia. Verifica-se a reafirmação dessa assertiva na fala de diferentes sujeitos da pesquisa, por exemplo, quando Confiança declara: "decidi ir para o programa Travessia porque já estava atrasada e tinha duas filhas pequenas na época, em 2007. Para terminar os estudos logo, fiz essa opção”. Situação semelhante é revelada por Satisfação, ao pontuar: "Eu sou do interior, e a gente sabe que no interior é muito difícil a gente terminar os estudos lá, então eu vim morar aqui (Recife) e estava muito atrasado nos estudos".

Consideramos que o interesse dos sujeitos por um programa educacional voltado para o aceleramento dos estudos, encurtando o período de duração do curso, corresponde plenamente ao que fora cotejado pelos propositores da política educacional que estamos analisando. Não obstante, há também argumentos que indicam a expectativa por algo mais, ou, nas palavras de Realização, "esperava um incentivo a mais do programa". Pode-se inferir que esse sujeito tinha expectativas de um curso que oportunizasse, essencialmente, aquisição de conteúdos sintonizados com o que é exigido na sequência da escolarização, no caso específico, o acesso ao ensino superior.

Havia, portanto, duas expectativas projetadas pelos sujeitos ao ingressarem no Travessia. A primeira, conforme já tratamos, diz respeito ao objetivo de concluir os estudos rapidamente, e foi reconhecida como exitosa pelos egressos das classes de aceleração de estudos que compunham o programa. Contudo, a segunda expectativa, que podemos sintetizar como desejo de "transformar a própria vida, sonhar com algo melhor para si", converteu-se em 


\section{pro.posıções}

http://dx.doi.org/10.1590/1980-6248-2017-0026

$e$-ISSN 1980-6248

sentimento de frustração, como concluiu Realização em seu depoimento, ao afirmar que "tudo ficou inacabado". O participante esperava ir além da conclusão do ensino médio e da regularização do fluxo escolar; na realidade, sua esperança era conquistar algo a mais para sua vida. Isto significa reconhecermos que "há vidas na escola, vida jovem, desejante de caminhos, de oportunidades de crescimento" (Abdalla, 2004, p. 84).

Cabe salientarmos que essa expectativa por novas oportunidades, por uma transformação de vida, corresponde, em essência, ao esperado da função social que a escola deve cumprir, mas que é relegada pelo programa em análise. Diante disto, podemos considerar que esse formato de processo de escolarização, ao privilegiar o encurtamento do tempo pedagógico, nivelando por baixo o que é ensinado, sacrifica, por consequência, o cumprimento do princípio da formação humana como compromisso essencial e inalienável da educação escolar.

É imprescindível reconhecermos que, nos anos iniciais do século XXI, constata-se um interesse mais aguçado das juventudes em intervir nas decisões do país, sobretudo no que concerne à construção da agenda de políticas públicas a ser assumida pelo Estado. Na realidade, há uma reconfiguração da condição juvenil em curso, manifesta em diferentes tempos, modos e espaços, com novas motivações e projeções para o futuro (Dayrell, 2007).

Portanto, emana dos jovens uma disposição para construir e difundir conhecimentos contextualizados com seu tempo histórico. Este fato reclama da escola a vivência de um programa educacional que vá além da conferência de títulos na idade ideal, ou do propósito de regularizar o fluxo escolar. Para tanto, é preciso levarmos em consideração temas didáticopedagógicos sintonizados com as questões sociais do tempo e dos lugares em que estão inseridos os sujeitos que compartilham dos processos escolares. Tal perspectiva é diametralmente oposta à opção por modelos educativos padronizados e difundidos indistintamente para diferentes contextos educacionais.

\section{A vivência dos sujeitos no programa}

Abordaremos, nesta seção, elementos referentes às trajetórias dos sujeitos no programa. Sistematizamos os trechos dos depoimentos em três blocos: o primeiro trata dos limites do 


\section{pro.posıções}

http://dx.doi.org/10.1590/1980-6248-2017-0026

\section{$e$-ISSN 1980-6248}

tempo pedagógico disponibilizado; o segundo faz referência à precariedade do trabalho docente; e o terceiro ressalta o aprender a conviver com o outro como maior contributo do programa.

No primeiro bloco exploramos o reconhecimento dos sujeitos sobre o tempo exíguo para o desenvolvimento de aprendizagens. A esse respeito, Persistência comenta que "às vezes, quando eu pensava que a aula ia começar, já tinha terminado. Por exemplo, a Era Vargas, se resumia em duas teleaulas, brincadeira né?". Esta fala sintetiza bem o reconhecimento dos sujeitos a respeito da insuficiência do tempo pedagógico nas classes de aceleração de estudos.

Esta constatação é reiterada por outros sujeitos da pesquisa, explicitando estranhamento com a organização e o método de ensino. É o caso de Conquista, que revela:

quando cheguei ao programa, não estava acostumada com aquele tipo de aula. Foi tudo muito acelerado, muito corrido, até os professores tinham que correr com os conteúdos, porque chegava a supervisora e dizia: Vamos terminar logo, olha o tempo!

Vale salientar, a partir desse trecho do depoimento de Conquista e dos demais alunos egressos entrevistados neste estudo, que o "tempo" constituía o principal fator de limitação para a construção de conhecimentos. Essa relação de causa e efeito é explicitada por Superação, quando revela: "eu penso que esse programa não deveria existir. Se voltasse o tempo, eu ia para o ensino regular, porque é mais completo e a gente tem as matérias mais certas, não é tudo passado, assim, só por cima".

O conjunto dos depoimentos realça a insuficiência de tempo para que os estudantes possam compreender e apreender o que está sendo trabalhado nas aulas. A fala de Conquista apontando que "até os professores tinham que correr com os conteúdos, pois essa prática seria cobrada pela supervisora" demonstra um descompasso entre o que o docente precisa trabalhar, em termos de conteúdos e situações didático-pedagógicas, e o tempo que efetivamente é disponibilizado para a conclusão das etapas do programa. Com isso, podemos inferir que há reconhecimento de que o propósito da política é apressar o repasse de conteúdos, mesmo que tanto o estudante quanto os professores e gestores envolvidos com o programa saibam que não há êxito no processo de ensino e aprendizagem.

É pertinente destacar que o movimento pela ampliação de dias e horas para o processo de escolarização, contemplado pela LDB/1996, nos artigos 24 e 31, que estabelece o mínimo de 800 horas distribuídas ao longo de 200 dias letivos, se sustenta no argumento da necessidade 


\section{pro.posições}

http://dx.doi.org/10.1590/1980-6248-2017-0026

$e$-ISSN 1980-6248

de ampliar o tempo pedagógico em cada ano das etapas da educação básica, inclusive para que seja possível garantir novas oportunidades de aprendizagem, respeitando os diferentes tempos de construção de saberes por cada indivíduo (Ministério da Educação, 2004, p. 40). Tal reconhecimento exige que os processos didático-pedagógicos desenvolvidos na e pela escola sejam concebidos e vivenciados com tempo pedagógico suficiente, especialmente quando se trata de estudantes com histórico de repetência, abandono e evasão escolar.

Concordamos com Arroyo (1997) quando este autor chama a atenção para o fato de que as questões pedagógicas e metodológicas merecem ser tratadas com seriedade e relevância na discussão da multirrepetência, para que não se incorra no risco de uma ineficácia permanente na superação desse quadro de distorção idade/série escolar, sobretudo quando se adota o encurtamento do tempo pedagógico como estratégia para corrigir o fluxo na educação básica.

Essa incompatibilidade entre o tempo pedagógico determinado pelo programa Travessia e a matriz curricular estabelecida para o ensino médio é ainda agravada por outro aspecto observado pelos sujeitos: o despreparo dos docentes para desenvolver a prática pedagógica, subtema que exploraremos na sequência.

Os trechos de fala que passaremos a discutir explicitam limitações pedagógicas percebidas pelos estudantes a respeito do trabalho desenvolvido pelos professores. Sobre essa matéria, Felicidade afirma que

para conseguir aprender, já cheguei, na época, até a direção da escola e disse: Rapaz, dá não! O professor mesmo tá perdido! Nós tamo perdido e a gente vai fazer como? Isso até o meio do Travessia, e a gente vai fazer como? Alguns professores diziam que ainda iam pra uma capacitação com três meses. Então, a gente tinha que pedir ajuda aos outros pra tirar as dúvidas. Tinha aluno que já tinha feito o $1^{\circ}$ ano, era mais novo e pegava as coisas mais rápido e ajudava os outros, e, quando sabia uma coisinha a mais, ajudava também até o professor.

Este trecho traduz a problemática revelada nas entrevistas dos sujeitos ao longo da pesquisa, que pretendemos colocar em relevo aqui: o quadro de despreparo do profissional docente, contratado temporariamente pelo programa Travessia, para lidar com a peculiaridade da ação que lhe é requisitada nas classes de aceleração de estudos.

Por sua vez, o trecho do depoimento de Persistência revela emblematicamente essa percepção dos sujeitos: 


\section{pro.posıções}

http://dx.doi.org/10.1590/1980-6248-2017-0026

$e$-ISSN 1980-6248

Tem uma coisa que eu achei grotesco. É até falta de ética falar isso, mas, por ser ele, o meu professor de português no programa, observei erros grotescos e alguns alunos até o corrigiam. Eu pensava: Esse cara está me ensinando? Eu achava aquilo ali o fim, porque você sai de casa, vindo do trabalho cansado e saber que eu estava ali só para pegar minha ficha 19, só porque isso é necessário, ter o ensino médio, porque aquilo não ia ter qualidade nenhuma para mim.

Devemos relembrar quão complexo é o exercício da docência nesse programa. Conforme já mencionamos, o docente assume a responsabilidade de trabalhar todas as disciplinas que compõem o currículo do ensino médio, não apenas a disciplina cuja formação inicial no ensino superior respalda seu exercício profissional. Evidentemente, isso não retira a gravidade da alusão que o sujeito faz aos supostos "erros de português", independentemente de se tratar ou não de um profissional com formação específica nessa área.

O fato é que se relata essa experiência com sentimento de frustração, uma vez que parece não haver a confiança necessária no trabalho desenvolvido pelo professor. Por outro lado, ao formatar o programa Travessia com as restrições de tempo pedagógico ora evidenciadas, além da exigência de atuação de apenas um professor no conjunto das disciplinas curriculares do ensino médio, entendemos que o próprio órgão gestor do sistema estadual de educação não garante as condições básicas para que os profissionais docentes desenvolvam exitosamente suas funções.

A percepção de que o trabalho docente foi considerado aquém do esperado pelos indivíduos é ainda reforçada no trecho de entrevista a seguir, quando Conquista revela: "aprendi porque estudava em casa, lendo na internet. $\mathrm{O}$ que achei ruim foi porque tudo era muito resumido nos assuntos e às vezes o professor não conseguia tirar minhas dúvidas". O destaque não parece ser a iniciativa de pesquisa do estudante, mas o fato de ser a consulta na internet que o faz convicto de que aprendeu alguma coisa, até porque o professor nem mesmo conseguia dirimir suas dúvidas.

$\mathrm{Na}$ realidade, por óbvio, no afã de corresponder ao que não lhe compete (pelo menos do ponto de vista da formação inicial), o docente acaba se desvalorizando, inclusive por não poder desenvolver com qualidade o que de fato constitui sua incumbência profissional. Ao mesmo tempo, acaba desvalorizado pelos discentes, que relacionam suas dificuldades de aprendizagem no curso essencialmente aos problemas de atuação docente, e pela gestão do sistema estadual de educação, que focaliza o exercício da docência em detrimento de requisitos 


\section{pro.posıções}

http://dx.doi.org/10.1590/1980-6248-2017-0026

\section{$e$-ISSN 1980-6248}

imprescindíveis, como a exigência de formação inicial para a área de sua atuação, a garantia de salário e perspectiva de carreira, além de condições de trabalho adequadas.

Esse quadro de atuação docente no programa pode ser considerado, como disse Perrenoud (1997, p. 11),

um "métier" complexo, denominado por Freud de "missão impossível" ... pensar a formação de professores é pensar na complexidade de uma profissão que interage com polaridades como sucesso/insucesso do próprio aluno e do próprio empreendimento educativo [ênfase no original].

Um exemplo dessa polaridade, observada pelo autor, é justamente o caso que estamos tratando, ao analisarmos a percepção dos egressos do programa Travessia. Nesse contexto, o professor é levado a abdicar suas próprias convicções didático-pedagógicas, uma vez que o exercício de sua profissão é regulado por modelos pedagógicos engessados e pré-estabelecidos por uma organização gestora localizada à parte do lócus de atuação dos próprios docentes e discentes.

Tais considerações indicam que o modelo de política de aceleração de estudos, quando levado a efeito por meio de uma prática pedagógica dissociada da complexidade inerente ao processo de ensino-aprendizagem, deve ser concebido como uma forma de reprodução do fracasso escolar. A esse respeito, apesar de reconhecermos a redução do número de estudantes com distorção idade/série escolar no ensino médio em Pernambuco, cabe considerar que tal conquista não tem sido percebida pelos sujeitos sociais como garantia de melhoria na qualidade do processo formativo, nem da articulação da escola à dinâmica social em que os estudantes estão inseridos (Dourado, 2004).

Passamos a discutir o item do terceiro bloco desta seção. Trata-se do reconhecimento de que a convivência entre os alunos constitui o maior diferencial positivo da experiência escolar vivida no âmbito do programa Travessia.

É importante percebermos que o fortalecimento das interações cotidianas entre os alunos do programa Travessia tem como principal justificativa a necessidade de compensar aprendizagem não alcançada no processo de ensino mediado pelo professor. A seguir apresentamos o que, em essência, foi enaltecido como contributo do trabalho em grupo. Iniciamos com o depoimento de Satisfação, que tece a seguinte consideração: 


\section{pro.posıções}

http://dx.doi.org/10.1590/1980-6248-2017-0026

quando o professor não sabia explicar, a gente se juntava nos grupos, e estudava em grupo, com muitas pessoas, com experiência. Tem pessoas que já estudou e a gente se reunia ali .... A gente sabe que o professor tá ali para nos ensinar, mas quando a gente quer realmente passar alguma coisa da gente, a gente colaborava também.

Por sua vez, Esperança declara: "eu gostei da forma de trabalhar em conjunto, com outras pessoas, as amizades que fiz, a comunicação e a forma de me expressar perante o grande público ...”. Esse relato nos permite inferir a reafirmação do significado das atividades em grupo ao longo da vivência no programa, externado anteriormente por Satisfação.

Os sujeitos da pesquisa reportaram-se aos momentos de convivência promovidos pelos trabalhos em grupo como um recurso metodológico favorável ao crescimento sociointerativo, reconhecendo que essa experiência surtiu efeitos positivos, principalmente o aprendizado de formas de se expressar em público. Esse entendimento é também compartilhado por Realização, que externou sua percepção sobre esse tema da seguinte forma:

O pouco que a gente teve, foi a gente aprender a ser amigo com as pessoas, em grupo ... A gente fazia um círculo e a gente falava e cada um dava seu depoimento. Foram muito interessantes nesse sentido as aulas, mas o ruim que não foi mais aproveitado pelo tempo reduzido, as faltas dos professores e a aprendizagem por cima.

Vê-se que, por um lado, as atividades em grupo são reconhecidas como boa estratégia para superar dificuldades de aprendizagem e também como momentos de construção de amizades entre os sujeitos. Por outro lado, não se infere a repercussão dessa estratégia didática na melhoria da construção de conhecimentos, uma vez que o sujeito conclui seu depoimento acusando a superficialidade da aprendizagem ao longo das aulas. De fato, é justo reconhecermos a percepção dos sujeitos de que o programa proporcionou a socialização e a melhoria da comunicação, construto capaz de reverberar na elevação da autoestima dos indivíduos, especialmente para mobilizar sua participação em espaços de promoção da cidadania, tema que colocamos à prova na sequência do texto.

\section{Narrativas sobre efeitos do programa Travessia}

Este subitem é dedicado à análise das percepções dos sujeitos sobre a repercussão do programa Travessia no que diz respeito à sequência dos estudos, à inserção no mundo do trabalho e à prática cidadã na trajetória de vida dos alunos egressos. Iniciamos a abordagem pela 


\section{pro.posições}

http://dx.doi.org/10.1590/1980-6248-2017-0026

\section{$e$-ISSN 1980-6248}

compilação e análise de trechos de falas sobre o exercício profissional dos sujeitos após a conclusão do programa:

Continuo do mesmo jeito, não tive transformação nenhuma não, a não ser através do emprego de porteiro, mas eu mesmo corri atrás. E a questão dos estudos, que parei e não prossegui numa faculdade. Esse ano ainda eu pensei em fazer, como muitas vezes pensei e até desisti, mas porque esse ano eu estou trabalhando à noite, aí fica muito puxado. (Realização)

Esse trecho da fala de Realização ilustra enfaticamente o sentimento de desencanto ao relatar os efeitos do programa em sua vida, especialmente por não ter conseguido seguir com o processo de escolarização, ficando frustrado o ideal de ingressar em um curso superior. A revelação de que, em sua vida cotidiana, o trabalho tem sido "puxado" também demonstra que a promessa, propagada ao longo do curso, de que a profissionalização constitui um dos pilares do processo formativo na modalidade de ensino que estamos analisando, na realidade, ainda não surtiu esse efeito, uma vez que prevalece o subemprego ou a vinculação empregatícia sazonal.

Conforme já anunciamos, foi possível constatar que o teor da avaliação de Realização sobre o programa é explicitado no depoimento de outros sujeitos da pesquisa. O fragmento do relato de Felicidade reforça a ênfase que tem sido percebida na fala dos sujeitos, ao se referirem à irrelevância do programa quando tratamos de sua relação com possíveis perspectivas de empregabilidade formal.

Quando eu terminei o programa Travessia eu tava empregado, eu era emplacador de carro, mas teve o corte da empresa lá. Quando nós saímos desse emprego, fui para uma transportadora. Entrei lá como carregador e passei para conferente. Hoje, eu não estou trabalhando. Tava numa empresa de ônibus como cobrador, mas o horário puxado, estresse demais. Mas, acho que topo tudo através do programa Travessia, não para qualquer concurso que tiver, mas qualquer empreguinho dá para encarar sem medo. Hoje eu vendo coxinha e caldo de cana e quero melhorar para sustentar minha família.

Portanto, os depoimentos revelam que a dependência do subemprego para prover a sobrevivência dos sujeitos não foi alterada após a conclusão do ensino médio no programa Travessia. O discernimento de Felicidade de que não é possível galgar uma vaga de emprego por meio de concurso, devido ao baixo nível de formação que lhe fora ofertado pelo programa, restando-lhe a consciência de que só é alcançável "qualquer empreguinho", assim como a ponderação feita por Esperança, em tom de interjeição, "Estou empregada sim!", seguida da ressalva "mas, não no emprego muito bom não, sou empregada doméstica", sintetizam a ideia 


\section{pro.posıções}

http://dx.doi.org/10.1590/1980-6248-2017-0026

de irrelevância da aceleração de estudos quanto à expectativa de inserção dos egressos no mundo do trabalho formal.

$\mathrm{Na}$ realidade, o que fica evidente é a baixa estima dos sujeitos por se sentirem despreparados para um trabalho condizente com a titulação obtida com a conclusão do ensino médio, razão pela qual também foi notável o reconhecimento dos sujeitos de que, se tivessem nova oportunidade, não optariam por classes de aceleração de estudos. Cabe ponderarmos que a elevação da escolaridade não garante necessariamente mobilidade social, por isso, não deveria ser estranha a constatação de que, mesmo com a conclusão do ensino médio, os egressos do programa Travessia não conseguiram a inserção em postos de trabalho formais e em atividades por eles desejadas. Contudo, chamamos a atenção para a ineficiência do programa nesse tema, pois os sujeitos que atenderam ao seu chamado e se matricularam no curso foram informados de que se tratava de uma política educacional que reverberaria em três dimensões na vida de seus egressos: continuidade de estudos em níveis subsequentes, inserção no mundo do trabalho formal e prática cidadã nos diversos espaços sociais. Portanto, há aqui um registro, respaldado nos depoimentos dos sujeitos, de limitações em relação ao que é prometido pelo próprio programa.

Sobre a sequência dos estudos, Confiança reconhece: "hoje eu faria o ensino regular, pelo fato que eu não aprendi muito. Eu não aprendi o bastante para encarar um vestibular, ou coisa parecida". O trecho de entrevista a seguir retoma o cerne da argumentação de Confiança e nos permite aprofundar a interpretação das razões que levam os sujeitos a questionarem a efetividade do programa Travessia.

Eu esperava sair mais bem capacitado e com a qualidade bem melhor em termos de conhecimentos, pra entrar na faculdade com a cabeça bem mais fresca, né? Na verdade, não ocorreu isso porque o programa é muito corrido. E por conta de alguns alunos que não conseguiam pegar tudo, tínhamos que ficar na repetição do mesmo conteúdo. Então [houve] muito atraso nos conteúdos, daí que passavam a mesma aula, do mesmo conteúdo, e pra mim foi muito fraco, me prejudicou muito. Se eu fosse elencar aspectos positivos, eu posso dizer que ficou de bom só à ficha 19. E o negativo, foi que me prejudicou muito. Eu entrei no Travessia e já tinha cursado o $1^{\circ}$ ano médio em classes do regular, daí eu entrei no Travessia para continuar os estudos. Então, nem me capacitei e nem relembrei o que eu já tinha aprendido antes.

Percebe-se que as falas analisadas reafirmam o baixo nível da formação no programa, mas também revelam a consciência de que o processo formativo na escola regular constitui alternativa recomendável, mesmo para o grupo com elevada distorção idade/série escolar. 


\section{pro.posıções}

http://dx.doi.org/10.1590/1980-6248-2017-0026

$e$-ISSN 1980-6248

Por fim, analisaremos dados da pesquisa referentes aos possíveis efeitos do programa na prática cidadã de seus egressos. Iniciamos com a exposição do trecho do depoimento de Conquista:

Apesar de ser ainda novo, eu já tinha uma formação para a vida. Tem umas coisas na minha vida que eu já tinha comigo, com relação à formação cidadã, porque ninguém muda visão de mundo, a gente já concebe isso antes, e minha opinião sobre as coisas ninguém muda. Sobre a melhoria da qualidade de vida, esse programa não me proporcionou nada, a relação com minha família continua a mesma, boa para minha vida. Agora, me senti incluído socialmente mesmo quando entrei na faculdade, quando conheci pessoas diferentes com a cabeça mais aberta, que têm um conhecimento maior das coisas, isso ajuda no seu perfil, tem pessoas que agregam valores e o Travessia não agregou nada disso.

Esse trecho serve para explicitarmos o que, em essência, foi exposto pelo conjunto dos sujeitos a respeito da repercussão do programa no fomento de práticas cidadãs de seus egressos. Uma das percepções coincidentes entre os sujeitos foi a de que o envolvimento com ações cidadãs constitui uma prática assumida por esses indivíduos antes do programa, o que podemos constatar na fala de Conquista, quando diz que "tem umas coisas na minha vida que eu já tinha comigo, com relação à formação cidadã”, mas também podemos reconhecer semelhante entendimento na fala de Satisfação, ao considerar que "como cidadão eu já tinha isso, mas ali era uma família, quando a gente forma grupo a gente vai ter uma amizade, a gente vai fazer uma família, então acredito que [o Travessia] também foi útil nessa parte”.

Outra constatação a partir das falas dos sujeitos sobre a prática cidadã diz respeito à afirmação coesa de que o aprimoramento das relações interpessoais constituíra o mais importante legado do curso. Tal entendimento pode ser exemplificado com o trecho de fala de Esperança: "fiz amizades com os colegas que me incentivaram a continuar estudando, mas consegui pouca coisa até agora. Minha relação com a família melhorou também, acho que dei um passo à frente na minha vida".

Esse depoimento, por um lado, enaltece uma experiência positiva no programa e até com relação à melhoria da convivência familiar; por outro lado, não explicita exercício de ações cidadãs no contexto social mais amplo, conforme tem sido instigado e esperado dos sujeitos egressos. 


\section{pro.posições}

http://dx.doi.org/10.1590/1980-6248-2017-0026

\section{$e$-ISSN 1980-6248}

\section{Considerações finais}

Propusemo-nos neste estudo a analisar a percepção de alunos egressos do Travessia acerca dos possíveis efeitos do programa no enfrentamento da histórica distorção idade/série na rede estadual de ensino de Pernambuco, com ênfase na repercussão dessa política de correção de fluxo estudantil como estratégia de superação do fracasso escolar. Trata-se de um estudo exploratório, porque até o momento da coleta de dados não encontramos outros estudos referentes a essa unidade federativa para subsidiar análises comparativas.

Precisamos reconhecer que, com o advento do programa Travessia, registra-se uma tendência de correção do fluxo escolar no ensino médio da rede pública estadual de Pernambuco, uma vez que o percentual de distorção idade/série escolar nesta etapa atingia 61\% em 2007 e foi reduzido para 36,4\% em 2013. Entretanto, a análise dos dados revela que as expectativas projetadas para a melhoria de vida dos sujeitos egressos, quanto à continuidade dos estudos, à maior inserção no mundo do trabalho e à mobilização de iniciativas cidadãs, não foram alcançadas.

Os depoimentos analisados realçam que a opção do programa por reduzir o tempo pedagógico disponível para a vivência curricular, combinada com a concentração dos componentes curriculares do ensino médio sob a responsabilidade de um único professor, resultou na manutenção de problemas de aprendizagem. Tal quadro gerou uma prática marcada tanto pela superficialidade do trato dos conteúdos, quanto pelo despreparo da ação docente para lidar com a diversidade e complexidade dos conhecimentos e situações didáticopedagógicas inerentes ao processo de ensino-aprendizagem que se espera no ensino médio.

Com efeito, o conjunto de ações para enfrentar a distorção idade/série configurou-se como fragmentado e fragmentador da própria sequência de escolarização, bem como da ação desenvolvida pelo profissional da educação. Isso porque é descontextualizado de uma concepção de política pública de educação mais ampla, que de fato priorize a formação, as reais condições de atuação docente e a aprendizagem significativa como referencial para a qualidade social da educação básica almejada.

O ritmo acelerado do processo de ensino e a baixa produção de conhecimentos, constatados pelos sujeitos, nos respaldam a considerar que programas educacionais imbuídos 


\section{pro.posições}

http://dx.doi.org/10.1590/1980-6248-2017-0026

\section{$e$-ISSN 1980-6248}

do propósito de uma formação integral, que respeitem os diferentes ritmos de aprendizagem dos alunos, não condizem com o modelo de classes de aceleração de estudos aqui analisado.

Tal constatação tem singular importância para corroborar a análise sobre o formato de política pública a ser mobilizado com fins de atender os sujeitos sociais ainda excluídos da educação formal, sobretudo no atual contexto de vigência do Plano Nacional de Educação (2014-2024), que reafirma, em sua Estratégia 3.5, o interesse em manter e ampliar programas e ações de correção de fluxo do ensino fundamental, por meio do acompanhamento individualizado do(a) aluno(a) com rendimento escolar defasado e pela adoção de práticas como aulas de reforço no turno complementar, estudos de recuperação e progressão parcial, de forma a reposicioná-lo no ciclo escolar compatível com sua idade (Lei n ${ }^{\circ} 13.005$, de 25 de junho de 2014).

É coerente reconhecermos que os programas de correção de fluxo escolar constituem ações emergenciais para minimizar um dos problemas cruciais e históricos da educação brasileira e que persiste carecendo de ações mais amplas e consistentes, contemplando não somente o objetivo de corrigir a distorção idade/série escolar, mas também o de promover resultados qualitativos na vida dos sujeitos sociais que vivenciem essa modalidade de política educacional.

Se os programas de aceleração de estudos têm sido concebidos e defendidos pelo poder público como iniciativas fundamentais para romper o ciclo de repetência, evasão e/ou abandono escolar, é preciso entender que tal perspectiva de política pública, por si só, não tem o alcance populacional nem o respaldo didático-pedagógico necessário para reverter o quadro do fracasso escolar que persiste no país, especialmente nas regiões geográficas historicamente desfavorecidas socioeconomicamente. Isto significa que o ideário da política pública deverá ir além do foco no aceleramento do fluxo escolar, devendo-se repensar o processo didáticopedagógico que favoreça a promoção de aprendizagens, a construção e difusão de saberes, habilidades e valores indispensáveis à formação humana que é compartilhada na e pela escola (Saviani, 2003).

Por fim, esperamos que os resultados deste estudo possam subsidiar discussões e ações nos mais diversos espaços que se interessem pela causa educacional, no sentido de mobilizar a defesa por políticas públicas de educação básica comprometidas com o enfrentamento do fracasso escolar, na perspectiva da construção de uma educação básica politicamente comprometida com seu papel de assegurar aos cidadãos a formação comum indispensável para 


\section{pro.posıções}

http://dx.doi.org/10.1590/1980-6248-2017-0026

\section{$e$-ISSN 1980-6248}

o exercício da cidadania e fornecer-lhes meios para progredir no trabalho e em estudos posteriores (LDB/1996).

\section{Referências}

Abdalla, V. (2004). O que pensam os alunos sobre a escola noturna. São Paulo: Cortez.

Andrade, E. F. (2013). Ação colegiada como estratégia de democratização da gestão educacional. Educação Unisinos, 17(2), 114-122.

Angelucci, C. B., Kalmus, J., Paparelli, R., \& Patto, M. H. S. (2004). O estado da arte da pesquisa sobre o fracasso escolar (1991-2002): um estudo introdutório. Educação e Pesquisa, 30(1), $51-72$.

Arroyo, M. G. (1997). Fracasso-sucesso: o peso da cultura escolar e do ordenamento da educação básica. In A. Abramowicz \& J. Moll (Orgs.), Para além do fracasso escolar (pp. 11 26). Campinas: Papirus.

Bardin, L. (2007). Análise de conteúdo (L. A. Rego \& A. Pinheiro, Trads.). Lisboa: Edições 70.

Cruz, E. B. G. (2007). Projeto de regularização do fluxo escolar: profilaxia ou tratamento? Dissertação de Mestrado, Universidade Federal da Bahia, Salvador.

Diretrizes Curriculares Nacionais Gerais da Educação Básica. (2013). Brasília, DF: MEC, SEB, Dicei.

Dayrell, J. (2007). A escola "faz" as juventudes? Reflexões em torno da socialização juvenil. Educação \& Sociedade, 28(100), 1105-1128.

Dourado, L. F. (2004). Gestão democrática da escola: movimentos, tensões e desafios. In A. M. Silva, \& M. A. S. Aguiar (Orgs.), Retrato da escola no Brasil (pp. 59-74). Brasília, DF: CNTE.

Granja, T. A. S. (2009). Políticas educacionais e programas compensatórios - o fracasso escolar e a exclusão: duas faces da mesma moeda. Campinas: Papirus.

Instituto Brasileiro de Geografia e Estatística. (2010). Pesquisa Nacional por Amostra de Domicílios: sintese dos indicadores de 2009. Rio de Janeiro: IBGE. 


\section{pro.posıções}

http://dx.doi.org/10.1590/1980-6248-2017-0026

\section{$e$-ISSN 1980-6248}

Instituto Nacional de Estudos e Pesquisas Educacionais Anísio Teixeira. (2007). Sinopse estatística da educação básica. Brasília, DF: Inep.

Instituto Nacional de Estudos e Pesquisas Educacionais Anísio Teixeira. (2013). Sinopse estatística da educação básica. Brasília, DF: Inep.

Instrução Normativa n 07, de 15 de outubro de 2008 (2008, 16 de outubro). Fixa diretrizes e orienta procedimentos para a correção de fluxo escolar no Ensino Médio, no âmbito da Rede Pública Estadual de ensino, através do Projeto Travessia. Diário Oficial do Estado de Pernambuco, seção 1.

Lei no 9.394, de 20 de dezembro de 1996 (1996, 23 de dezembro). Estabelece as Diretrizes e Bases da Educação Nacional. Diário Oficial da União, seção 1.

Lei no 13.005, de 25 de junho de 2014 (2014, 25 de junho). Aprova o Plano Nacional de Educação - PNE e dá outras providências. Diário Oficial da União, seção 1.

Levin, H., \& Soler, P. (1992). Escolas aceleradas: podem elas ser bem sucedidas no Brasil? Brasília, DF: Inep.

Lugli, R. G., \& Gualtieri, R. C. E. (2012). A escola e o fracasso escolar. São Paulo: Cortez.

Ministério da Educação (BR). (2004). Programa Nacional de Fortalecimento dos Conselhos Escolares Conselho Escolar: democratização da escola e a construção da cidadania. Brasília, DF: MEC, SEB.

Oliveira, J. B A. (2002). Correção de fluxo escolar: um balanço do programa Acelera Brasil (1997-2000). Caderno de Pesquisa, 116.

Parente, C. (2002). “Observação: Um percurso de formação, prática e reflexão”. In J. O. Formosinho (Org.), A supervisão na formação de professores I: da sala à escola (pp. 166-216). Porto: Porto Editora.

Perrenoud, P. (1997). Práticas pedagógicas, profissão docente e formação: perspectivas sociológicas (2a ed.). Lisboa: Dom Quixote.

Saviani, D. (2003). Escola e Democracia: teoria da educação; curvatura da vara, onz̧e teses sobre educação e politica (36a ed.). Campinas: Autores Associados.

Secretaria de Educação do Estado (PE). (2007). Projeto de aceleração de estudos do ensino médio. Recife. 


\section{pro.posıções}

http://dx.doi.org/10.1590/1980-6248-2017-0026

\section{$e$-ISSN 1980-6248}

Setúbal, M. A. (2000). Os programas de correção de fluxo no contexto das políticas educacionais contemporâneas. Em aberto, 17(71), 9-19.

Triviños, A. N. S. (1987). Introdução à pesquisa em Ciências Sociais: a pesquisa qualitativa em educaşão o positivismo, a fenomenologia, o marxismo. São Paulo: Atlas.

\section{Referências consultadas}

Dourado, L. F. (2007). Plano Nacional de Educação: avaliações e retomada do protagonismo da sociedade civil organizada na luta pela educação. In N. S. C. Ferreira (Org.), Políticas públicas e gestão da educação: polêmicas, fundamentos e análises (pp. 21-50). Brasília, DF: Líber Livro.

Submetido à avaliação em 16 de fevereiro de 2017; revisado em 19 de julho de 2018; aceito para publicação em 16 de março de 2019. 